\title{
Neighborhood Food Outlets, Diet, and Obesity Among California Adults, 2007 and 2009
}

\author{
Aiko Hattori, PhD; Ruopeng An, MPP, MPhil; Roland Sturm, PhD \\ Suggested citation for this article: Hattori A, An R, Sturm R. Neighborhood Food Outlets, Diet, and Obesity Among \\ California Adults, 2007 and 2009. Prev Chronic Dis 2013;10:120123. DOI: http://dx.doi.org/10.5888/pcd10.120123 芯.
}

PEER REVIEWED

\section{Abstract}

\section{Introduction}

Varying neighborhood definitions may affect research on the association between food environments and diet and weight status. The objective of this study was to examine the association between number and type of neighborhood food outlets and dietary intake and body mass index (BMI) measures among California adults according to the geographic size of a neighborhood or food environment.

\section{Methods}

We analyzed data from 97,678 respondents aged 18 years or older from the 2007 and 2009 California Health Interview Survey through multivariable regression models. Outcome variables were BMI, weight status of a BMI of 25.0 or more and a BMI of 30.0 or more, and the number of times per week the following were consumed: fruits, vegetables, sugarsweetened soft drinks, fried potatoes, and fast food. Explanatory variables were the number of fast-food restaurants, full-service restaurants, convenience stores, small food stores, grocery stores, and large supermarkets within varying distances (0.25 to 3.0 miles) from the survey respondent's residence. We adopted as a measure of walking distance a Euclidean distance within 1 mile. Control variables included sociodemographic and economic characteristics of respondents and neighborhoods.

\section{Results}

Food outlets within walking distance ( $\leq 1.0$ mile) were not strongly associated with dietary intake, BMI, or probabilities of a BMI of 25.0 or more or a BMI of 30.0 or more. We found significant associations between fast-food outlets and dietary intake and between supermarkets and BMI and probabilities of a BMI of 25.0 or more and a BMI of 30.0 or more for food environments beyond walking distance (>1.0 mile).

\section{Conclusion}

We found no strong evidence that food outlets near homes are associated with dietary intake or BMI. We replicated some associations reported previously but only for areas that are larger than what typically is considered a neighborhood. A likely reason for the null finding is that shopping patterns are weakly related, if at all, to neighborhoods in the United States because of access to motorized transportation.

\section{Introduction}

The relationship between neighborhood food environments and obesity occupies a central role in policy debates (1-4). A recurring theme is the notion of "food deserts," where access to healthful and affordable food is limited $(5,6)$. Food deserts are often identified by the absence of supermarkets or full-range grocery stores and by the presence of fast-food restaurants and convenience stores (6). Hypotheses that link the food environment with obesity claim that proximity to fast-food outlets, convenience stores, or small grocery stores undermines diet quality, whereas proximity to supermarkets or full-range grocery stores enhances it by providing healthful products, mainly fruits and vegetables (7). However, evidence is more tentative than often presented in the news media and in policy arguments $(7,8)$.

Associations between food environment measures and obesity are not reliably replicated, and dietary behaviors are not consistent with these associations (9). Varying definitions of "neighborhood" could also contribute to the inconsistency 
of results and lack of comparability of data. Few studies have examined the association between varying neighborhood sizes and dietary intake and weight status (10-12). The objective of this study was to examine the associations of number and type of neighborhood food environments with dietary intake and body mass index (BMI) measures by using definitions of "neighborhood" based on various geographic sizes. We analyzed data from the California Health Interview Survey.

\section{Methods}

We used data from the 2007 and 2009 waves of the California Health Interview Survey (CHIS), a random-digit-dial telephone survey of California's noninstitutionalized population (13). In 2007 and 2009, the CHIS included interviews of 98,662 adults aged 18 years or older. The sampling weights provided by CHIS account for unequal sampling probabilities and nonresponse to allow generalization to the study population. We limited our analysis to 97,678 adults aged 18 years or older, excluding $533(0.5 \%)$ pregnant women and $451(0.5 \%)$ respondents whose information was provided through a proxy interview.

Self-reported measures on dietary intake included the number of times per week the following were consumed during the month before the interview: fruits (excluding juices), vegetables (excluding fried potatoes), sugar-sweetened soft drinks (excluding diet soft drinks), and fried potatoes (including French fries, home fries, and hash browns). The measures also included the number of times fast food had been consumed in the week before the interview. The information was collected through questions in the following format: "During the past month ['or in the past 7 days' for fast-food consumption], how often did you eat [food item name]?” The question was often followed by clarification of the food items. The response was standardized to reflect mean per-week intake frequency.

Anthropometric measures included BMI, calculated as self-reported weight in kilograms divided by self-reported height in meters squared. We defined "overweight or obese" as a BMI of 25.0 or more and "obese" as a BMI of 30.0 or more, according to World Health Organization classifications for adults (14).

Whereas most large survey studies use a predefined administrative unit such as census tract or zip code to define neighborhood, we defined neighborhood on the basis of geographic distance from a respondent's residence, and we defined neighborhood food environment by counting the number of different types of food outlets within those distances. We drew circular buffers of varying radii (0.25, 0.5, 1.0, 1.5, and 3.0 miles) centered on each respondent's residential address. Because 1 mile is often used as a threshold for walkable distance (6), we considered distances of $0.25,0.5$, and 1.o miles to be within walking distance. We measured Euclidean distance (straight line distance between 2 points) using ArcMap 9.1 (ESRI, Redlands, California).

We used food outlet data from the 2008 release of InfoUSA (15). We overlaid food outlet locations on the buffers around respondents' residences and counted the number of different types of food outlets in each buffer. We classified fast-food restaurants, full-service restaurants, convenience stores, small food stores, mid-size grocery stores, and large supermarkets by using the North American Industry Classification System (NAICS) (16). NAICS does not have a code for fast-food restaurants; we identified 63 major fast-food franchises that have main menus that include items such as hot dogs, hamburgers, pizza, fried chicken, submarine sandwiches, or tacos by NAICS codes 72221105-6. Full-service restaurants were identified by NAICS codes 72211001-20; convenience stores, code 44512001; and small food stores (annual sales $<\$ 1$ million), mid-size grocery stores (annual sales of $\$ 1-\$ 5$ million), and large supermarkets (annual sales $>\$ 5$ million), codes $44511001-3$, respectively.

To examine the association between neighborhood food environment and dietary intake, we performed negative binomial regression analysis. The dietary intake measures were the dependent variables, and the numbers of different types of food outlets in the buffers were the explanatory variables. Negative binomial regression is a generalization of the Poisson model in which the Poisson parameter has a random component (17). We performed separate regressions for each dietary intake measure and buffer size, calculated average marginal effects (AMEs), which measure an estimated change in the outcome in the observed unit associated with 1 unit change in the regressor of interest, and applied the Bonferroni adjustment for multiple comparisons. We controlled for potentially confounding individual and neighborhood factors. Individual-level control variables included sex, age (in years and age squared), race/ethnicity (white, African American, Hispanic, Asian or Pacific Islander, Native American, other race/multirace), household size, annual household income (in natural logarithm), education (not a high school graduate, high school graduate, high school graduate but not college graduate, college graduate, and more than college degree), marital status (married, divorced/separated/widowed, single), parental status (has a child or has no child), physical activity (regular activity, some activity, sedentary), and survey year. Although we were interested in vehicle ownership, this information was not collected in CHIS 2009 and therefore not included in our analysis. Proxies for neighborhood-level control variables, which were obtained from 2000 Census data (18), included population density, median household income, and proportion of non-Hispanic white residents of a respondent's residential census tract. These factors did not match our definition of neighborhood for the explanatory variables, but they could be derived only from predefined administrative units. 
To examine the association between the neighborhood food environment and BMI measures, we regressed BMI (through ordinary least squares [OLS]) and its dichotomous cutoffs of BMI of 25.0 or more and BMI of 30.0 or more (through logistic regression) on the same set of explanatory and control variables. Again, we performed separate regressions for each buffer size, calculated AMEs for logistic regression models, and applied the Bonferroni adjustment for multiple comparisons. We then compared the significant associations of food environments with dietary intakes and BMI measures to examine the hypothesis that the neighborhood food environment influences BMI through its influence on dietary intakes.

We performed several sensitivity analyses: stratified analysis by urbanicity (urban vs nonurban residents) and income level (federal poverty level [FPL] $\leq 130 \%$ vs FPL $>130 \%$ ) and analysis by density (instead of raw counts) of food outlets by census tract (the number of food outlets in census tract per 1,000 population and the number of food outlets in census tract per square mile). We defined "low income" as FPL of $130 \%$ or less. All analyses were performed in Stata 12.1 (StataCorp LP, College Station, Texas). We weighted the regression using sampling weights and estimated $P$ values based on heteroscedasticity-robust standard errors obtained by using the Eicker-Huber-White sandwich estimator.

\section{Results}

Of the dietary items surveyed, mean intake was greater for fruits ( 7.7 times per week) and vegetables (6.9 times per week) than for sugar-sweetened soft drinks (2.2 times per week), fast food (1.5 times per week), or fried potatoes (0.9 times per week) (Table 1). Average BMI was 26.8; $57 \%$ of respondents were overweight or obese, and $22.7 \%$ were obese.

The number of food outlets per food outlet type in each buffer varied in the expected way: we found more small food stores and fast-food restaurants on average than other food outlet types (Table 2); large supermarkets and mid-size grocery stores were less common. We found an average of approximately 7 fast-food restaurants, 3 full-service restaurants, 2 convenience stores, 7 small food stores, 1 mid-size grocery store, and 2 large supermarkets in the 1-mile buffer. Low-income respondents were surrounded by more food outlets of each type, including mid-size grocery stores and large supermarkets, than were their wealthier counterparts.

Among all 5 buffer sizes, most (79\% [119/150]) of the effects of the number of food outlets on intake of food items were not significant. Eight effects were significant after applying Bonferroni's adjustment; 7 of these were clustered around larger buffer sizes (1.5 miles and 3.0 miles) and fast-food restaurants and large supermarkets (Table 3). The number of fast-food restaurants in the 3.0-mile buffer was positively associated with an increase in intake frequency of sugarsweetened soft drinks, fast food, and fried potatoes, and less frequent consumption of fruits and vegetables. By contrast, the number of large supermarkets within 1.5- and 3.0-mile buffers was associated with less frequent consumption of sugar-sweetened soft drinks.

Among all 5 buffer sizes, most (83\% [75/90]) of the effects of the number of food outlet types on BMI, and weight status of a BMI of 25.0 or more or a BMI or 30.0 or more were not significant. Seven effects were significant after applying Bonferroni's adjustment; these were significant in the larger buffer sizes and large supermarkets and fastfood restaurants. The number of fast-food restaurants in the 3.0-mile buffer was positively associated with the probability of a BMI of 25.0 or more but not with BMI or the probability of a BMI of 30.0 or more (Table 4). The number of large supermarkets in the 3.0-mile buffer was associated with lower BMI and lower probabilities of a BMI of 25.0 or more and a BMI of 30.0 or more. Some of these associations were also found in the 1.5- and 1.0-mile buffers.

More fast-food restaurants in the 3.0-mile buffer predicted increased frequency of consuming fried potatoes, sugarsweetened soft drinks, and fast food, decreased frequency of consuming vegetables, and a lower probability of a BMI of 25.0 or more. By contrast, the number of supermarkets was largely not associated with dietary intake, whereas more supermarkets within 1.0-, 1.5-, and 3.0-mile buffers predicted lower BMI.

When we stratified the analysis by urbanicity and FPL, we did not find the significant associations between the number of food outlet types and dietary intake or BMI measures among nonurban respondents and low-income respondents that we observed in unstratified analysis, but we did find them among their urban and wealthier counterparts.

When we used census tract data, only the association between the number of mid-size grocery stores in census tract per 1,00o population and fast-food consumption was significant after adjustment for multiple comparisons; we found no significant associations for the other food outlet types or BMI measures.

\section{Discussion}

Our study did not find strong evidence to support the hypothesis that the food environment within walkable distance is associated with the dietary intake or BMI measures of residents. We found some evidence that the food environment for larger, nonwalkable areas (1.5- and 3.0-mile buffers) is associated with dietary intake and BMI measures. Moreover, significant results for BMI measures do not match dietary intakes, except for the number of fast-food 
restaurants within a 3.0-mile buffer, which was simultaneously associated with increased frequency of consuming fried potatoes, sugar-sweetened soft drinks, and fast food, decreased frequency of consuming vegetables, and greater probability of being overweight or obese (a BMI of 25.0 or more). We found an association between BMI measures and supermarkets only for the 1.5- and 3.0-mile buffers, but those associations did not parallel dietary intake. In particular, we found no association between supermarkets and vegetable and fruit consumption at any buffer size. When we compared the density of food outlets on the basis of residential census tract instead of raw counts, we observed only 1 significant association (between the number of mid-size grocery stores in census tract per 1,00o population and fastfood consumption) and there were no significant associations between other types of food outlets and either BMI measures or dietary intake. Therefore, our data do not confirm previous data, especially data on the association between fast-food restaurants or supermarkets and dietary intake or BMI. The primary strength of this study is that we explored a range of distances from respondents' residential address, from areas smaller than census tracts to areas much larger, instead of using predefined units, such as census tracts or zip codes.

This study has several limitations. First, we measured food outlet type, not the availability of certain foods. We obtained food outlet data from InfoUSA; business listings are rarely up-to-date or without error. One study reported only fair agreement between commercial data and field observations for supermarkets, grocery stores, convenience stores, and full-service restaurants and poor agreement for fast-food restaurants (19). The dietary intake questions we used did not provide guidance on serving size, and they asked about a small number of food items; hence, they did not allow examination of overall diet quality. The questions also had a long recall period of 1 month. BMI was calculated from self-reported height and weight; self-report tends to underestimate BMI (20-22). The study used data from California, and the results may not apply to other geographic regions or populations. Finally, this study used crosssectional data and was unable to establish causation.

The limitations of the data used in this study may have contributed to our null findings, but there are other, substantive reasons for finding a null relationship between of the number of food outlet types and dietary intake or BMI. A likely reason for our null findings is that food-shopping patterns are weakly related, if at all, to neighborhoods in the United States because of access to motorized transportation. Access to motorized transportation increases mobility and may limit the relevance of immediate food environments by allowing residents to travel beyond a walking distance. California has one of the highest rates of vehicle ownership (23); most of its population resides in metropolitan areas (24). Although the local food environment may be important for rural households (where residents are sparsely distributed) or households that lack access to motorized transportation, the sample size in our study may have been too small to detect associations affected by rural residence or car ownership. The most recent CARDIA study reports associations between fast-food restaurants in immediate neighborhoods and fast-food consumption among low -income men but not for higher-income groups or neighborhoods outside walking distance, suggesting greater reliance on immediate food environments among low-income people who are less likely to own a car (11).

Food environment research has often been based on predefined administrative units, typically census tracts, which correspond to our smaller buffer sizes. In California, the median census tract corresponds to a buffer with a 0.5-mile radius; nationwide, the median census tract corresponds to a buffer with a 0.79-mile radius, both within the walkable distance of 1 mile (6). However, the 1-mile definition may no longer be relevant in the motorized society of the United States and California. Further research on varying sizes of neighborhoods is warranted to understand people's foodshopping travel patterns and how the patterns expose people to different food environments.

In the literature of food deserts, it is often argued that lower-income communities have reduced access to foods. However, these results are often based on density measures (eg, stores per capita in census tract) $(25,26)$. When we compared the density of food outlets among low- and higher-income respondents by using data on density based on census tracts (the number of food outlets in census tract per 1,000 population), the densities of supermarkets and fullservice restaurants were lower among low-income people. However, low-income areas are also much more densely populated, so the distance between a residence and a food outlet may be a more relevant criterion than density. In our definitions of neighborhoods, which used circular buffers centered on individuals' homes, neighborhood sizes are identical for all individuals and the dependent variable (the number of food outlet types per buffer) has the same physical meaning. Using this uniformly defined measure, we found that low-income respondents had greater access to each type of food outlet. Our findings are consistent with a report by the US Department of Agriculture, which found a smaller median distance to the nearest supermarket among low-income individuals (compared with higher-income individuals) in urban areas (6). Although predefined administrative units (eg, census tracts) may be more feasible for monitoring purposes, measures reflecting the proximity of food outlets may more reliably identify disadvantaged communities.

The concept of neighborhood food environments has been the focus of the news media and policy makers, yet the evidence is not clear on whether promoting or discouraging a particular type of food outlet is an effective approach to promoting healthful dietary behaviors and weight status. Initial findings in a new area of research - such as food environments - may be qualified over time, and both exact replication and conceptual replication of previous findings using alternative data sources and methods is a central theme for advancing scientific knowledge and informing 
policies. No single study completely addresses a research question, and this study can only contribute another data point. However, at least in California, the relationship between neighborhood food outlets and dietary intake or BMI is subtler than the relationship presented in the news media. The relationship appears to exist in larger geographic areas rather than within walking distances or in a typical urban census tract, larger areas that are arguably outside what we consider to be a neighborhood.

\section{Acknowledgments}

This project was supported by the following: grant no. T32 HSooo046 from the Agency for Healthcare Research and Quality (A.H.), Jim Lovelace Foundation 2010-2011 Dissertation Award (R.A.), and grant no. Ro1HDo57193 from the National Institute on Child Health and Human Development (R.S.). The content is solely the responsibility of the authors and does not necessarily represent the official views of the Agency for Healthcare Research and Quality or the National Institute on Child Health and Human Development.

\section{Author Information}

Corresponding Author: Aiko Hattori, PhD, Carolina Population Center, University of North Carolina at Chapel Hill, CB no. 8120, University Square, 123 W Franklin St, Chapel Hill, NC 27516-2524. Telephone: 919-966-3873. E-mail: hattori@email.unc.edu. At the time of the study, Dr Hattori was at the University of California, Los Angeles.

Author Affiliations: Ruopeng An, Pardee RAND Graduate School, Santa Monica, California; Roland Sturm, RAND Corporation, Santa Monica, California.

\section{References}

1. News release: Obama administration details healthy food financing initiative. Washington (DC): US Department of Health and Human Services. http://www.hhs.gov/news/press/2010pres/02/20100219a.html. Updated January 3, 2011. Accessed February 11, 2012.

2. White House Task Force on Childhood Obesity. Solving the problem of childhood obesity within a generation White House Task Force on Childhood Obesity report to the President. Washington (DC): Executive Office of the President of the United States; 2010.

3. Strategic plan 2010-2015. Washington (DC): US Department of Health and Human Services. http://www.hhs.gov/secretary/about/priorities/priorities.html. Updated May 2012. Accessed January 11, 2012.

4. National Prevention Council. National prevention strategy. Washington (DC): US Department of Health and Human Services, Office of the Surgeon General; 2011.

5. Smith D, Cummins S. Food deserts. In: Cawley J, editor. The Oxford handbook of the social science of obesity. New York (NY): Oxford University Press; 2009. p. 452-62.

6. Ver Ploeg M, Breneman V, Farrigan T, Hamrick K, Hopkins D, Kaufman P, et al. Access to affordable and nutritious food: measuring and understanding food deserts and their consequences. Washington (DC): US Department of Agriculture; 2009.

7. Larson NI, Story MT, Nelson MC. Neighborhood environments: disparities in access to healthy foods in the US. Am J Prev Med 2009;36(1):74-81. CrossRef 空 PubMed 空

8. Feng J, Glass TA, Curriero FC, Stewart WF, Schwartz BS. The built environment and obesity: a systematic review of the epidemiologic evidence. Health Place 2010;16(2):175-90. CrossRef 鹿 PubMed 嫁

9. Giskes K, van Lenthe F, Avendano-Pabon M, Brug J. A systematic review of environmental factors and obesogenic dietary intakes among adults: are we getting closer to understanding obesogenic environments? Obes Rev 2011;12 (5):e95-106. CrossRef 逄 PubMed 處

10. An R, Sturm R. School and residential neighborhood food environment and diet among California youth. Am J Prev Med 2012;42(2):129-35. CrossRef 图 PubMed 虑

11. Boone-Heinonen J, Gordon-Larsen P, Kiefe CI, Shikany JM, Lewis CE, Popkin BM. Fast food restaurants and food stores: longitudinal associations with diet in young to middle-aged adults: the CARDIA study. Arch Intern Med 2011;171(13):1162-70. CrossRef 图 PubMed 店

12. Jeffery RW, Baxter J, McGuire M, Linde J. Are fast food restaurants an environmental risk factor for obesity? Int J Behav Nutr Phys Act 2006;3:2. CrossRef 图 PubMed 图

13. CHIS California Health Interview Survey. Los Angeles (CA): UCLA Center for Health Policy Research. http://www.chis.ucla.edu/. Accessed November 13, 2011. 
14. Health topics: obesity. Geneva (CH): World Health Organization. http://www.who.int/topics/obesity/en/. Accessed February 20, 2012.

15. InfoUSA. Papillion (NE): Infogroup. http://www.infousa.com/. Accessed August 17, 2012.

16. North American Industry Classification System. Washington (DC): US Census Bureau. http://www.census.gov/eos/www/naics/. Updated June 19, 2012. Accessed November 13, 2011.

17. Hilbe J. Negative binomial regression. New York (NY): Cambridge University Press; 2011.

18. US Census Bureau. Census 2000 gateway. http://www.census.gov/main/www/cen20oo.html. Accessed December 1, 2012.

19. Powell LM, Han E, Zenk SN, Khan T, Quinn CM, Gibbs KP, et al. Field validation of secondary commercial data sources on the retail food outlet environment in the US. Health Place 2011;17(5):1122-31. CrossRef 图 PubMed 图

20. Gorber SC, Tremblay MS. The bias in self-reported obesity from 1976 to 2005: a Canada-US comparison. Obesity (Silver Spring) 2010;18(2):354-61. CrossRef 图 PubMed 图

21. Stommel M, Schoenborn C. Accuracy and usefulness of BMI measures based on self-reported weight and height: findings from the NHANES \& NHIS 2001-2006. BMC Public Health 2009;9:421. CrossRef 虔 PubMed 虑

22. Merrill RM, Richardson JS. Validity of self-reported height, weight, and body mass index: findings from the National Health and Nutrition Examination Survey, 2001-2006. Prev Chronic Dis 2009;6(4):A121. PubMed 图

23. Federal Highway Administration. Our nation's highways 2008. Washington (DC): US Department of Transportation; 2008.

24. State and county quickfacts. Washington (DC): US Census Bureau. http://quickfacts.census.gov/qfd/index.html. Accessed November 13, 2011.

25. Charreire H, Casey R, Salze P, Simon C, Chaix B, Banos A, et al. Measuring the food environment using geographical information systems: a methodological review. Public Health Nutr 2010;13(11):1773-85. CrossRef 逄 PubMed 迹

26. Fleischhacker SE, Evenson KR, Rodriguez DA, Ammerman AS. A systematic review of fast food access studies. Obes Rev 2011;12(5):e460-71. CrossRef 圈 PubMed 图

\section{Tables}

Table 1. Characteristics of Respondents and Census Tracts, California Health Interview Survey (CHIS), 2007 and 2009a

\begin{tabular}{|l|r|}
\hline \multicolumn{1}{|c|}{ Sharvey Respondents } & \multicolumn{1}{|}{ Value } \\
\hline \multicolumn{2}{|c|}{} \\
\hline Dietary intake, mean (IQR), no. of times consumed per week & $2.2(0-2)$ \\
\hline Sugar-sweetened soft drinks & $1.5(0-2)$ \\
\hline Fast food & $7.7(3-14)$ \\
\hline Fruits & $0.9(0-1)$ \\
\hline Fried potatoes & $6.9(3-7)$ \\
\hline Vegetables & $26.8(5.8)$ \\
\hline Body weight & $21,682(22.7)$ \\
\hline BMI, mean (SD), kg/m² & $39,690(49.5)$ \\
\hline Obese (BMI $\geq 30.0)$, no. (\%) & \\
\hline Male, no. (\%) & $45.0(17.4)$ \\
\hline Age & $2,328(961-3249)$ \\
\hline Age, mean (SD), y & \\
\hline Age squared, mean (IQR) & \\
\hline Race/ethnicity, no. (\%) & \\
\hline
\end{tabular}




\begin{tabular}{|c|c|}
\hline Characteristic & Value \\
\hline White, non-Hispanic & $65,437(48.8)$ \\
\hline African American, non-Hispanic & $4,416(5.9)$ \\
\hline Asian or Pacific Islander, non-Hispanic & $9,331(13.3)$ \\
\hline Native American, non-Hispanic & $1,135(0.9)$ \\
\hline Other race or multirace, non-Hispanic & $5,868(8.6)$ \\
\hline Hispanic & $11,491(22.5)$ \\
\hline No. of household members, mean (IQR) & $3.3(2-4)$ \\
\hline Natural logarithm of annual household income, mean (SD) & $10.7(1.5)$ \\
\hline \multicolumn{2}{|l|}{ Education, no. (\%) } \\
\hline Not a high school graduate & $9,623(16.2)$ \\
\hline High school graduate & $21,562(26.5)$ \\
\hline High school graduate but not college graduate & $19,900(17.6)$ \\
\hline College graduate & $29,363(26.5)$ \\
\hline More than college degree & $17,230(13.2)$ \\
\hline \multicolumn{2}{|l|}{ Marital status, no (\%) } \\
\hline Married & $55,405(61.7)$ \\
\hline Divorced/separated/widowed & $27,571(14.4)$ \\
\hline Single & $14,702(24.0)$ \\
\hline Have a child, no. (\%) & $25,206(33.9)$ \\
\hline \multicolumn{2}{|l|}{ Physical activity level, no. (\%) } \\
\hline Sedentary & $24,042(24.2)$ \\
\hline Some activity & $45,240(46.7)$ \\
\hline Regular activity & $28,396(29.1)$ \\
\hline CHIS participants interviewed in 2009, no. (\%) & $47,114(50.6)$ \\
\hline Urban residence, no. (\%) & $79,180(88.9)$ \\
\hline \multicolumn{2}{|c|}{ Census Tractsb } \\
\hline Population per square mile, mean (IQR), no. & $8,025(2,398-10,151)$ \\
\hline Household income, median (SD), \$ & $69,127(34,346)$ \\
\hline Proportion of non-Hispanic whites, mean (SD), \% & $56.5(21.1)$ \\
\hline
\end{tabular}

Abbreviations: IQR, interquartile range; BMI, body mass index; SD, standard deviation.

a Percentages and means are weighted using CHIS sampling weights. Counts are unweighted. Percentages may not sum to 100 because of rounding.

b Data source: US Census Bureau (18).

Table 2. Number of Food Outlets by Type, Buffer Sizea, and Federal Poverty Level (FPL), California, 2007 and 2009

\begin{tabular}{|l|c|r|r|}
\hline & \multirow{2}{|c|}{ Mean No. of Outlets } \\
\cline { 3 - 4 } Food Outlet Type, by Buffer & No. of Outlets, Mean (95\% CI) & FPL $\leq \mathbf{1 3 0 \%}$ & FPL $\mathbf{3 1 3 0 \%}$ \\
\hline 0.25-Mile radius & $0.45(0.43-0.47)$ & 0.57 & 0.42 \\
\hline Fast-food restaurant
\end{tabular}




\begin{tabular}{|c|c|c|c|}
\hline \multirow[b]{2}{*}{ Food Outlet Type, by Buffer } & \multirow[b]{2}{*}{ No. of Outlets, Mean ( $95 \% \mathrm{CI})$} & \multicolumn{2}{|c|}{ Mean No. of Outletsb } \\
\hline & & FPL $\leq 130 \%$ & FPL $>130 \%$ \\
\hline Full-service restaurant & $0.18(0.17-0.19)$ & 0.24 & 0.17 \\
\hline Convenience store & $0.15(0.15-0.16)$ & 0.22 & 0.14 \\
\hline Small food store & $0.56(0.53-0.59)$ & 1.02 & 0.44 \\
\hline Mid-size grocery store & $0.09(0.08-0.10)$ & 0.16 & 0.07 \\
\hline Large supermarket & $0.13(0.12-0.13)$ & 0.15 & 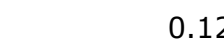 \\
\hline \multicolumn{4}{|l|}{0.5 -Mile radius } \\
\hline Fast-food restaurant & $1.92(1.88-1.97)$ & 2.31 & 1.82 \\
\hline Full-service restaurant & $0.74(0.71-0.76)$ & 0.84 & 0.71 \\
\hline Convenience store & $0.57(0.56-0.58)$ & 0.80 & 0.51 \\
\hline Small food store & $2.05(1.96-2.15)$ & 3.45 & $1.6 \mathrm{~S}$ \\
\hline Mid-size grocery store & $0.33(0.32-0.35)$ & 0.52 & $0.2 \varepsilon$ \\
\hline Large supermarket & $0.50(0.49-0.51)$ & 0.56 & $0.4 \varepsilon$ \\
\hline \multicolumn{4}{|l|}{ 1.0-Mile radius } \\
\hline Fast-food restaurant & $7.34(7.24-7.45)$ & 8.53 & 7.03 \\
\hline Full-service restaurant & $2.65(2.60-2.70)$ & 2.96 & 2.57 \\
\hline Convenience store & $1.99(1.95-2.03)$ & 2.62 & 1.82 \\
\hline Small food store & $7.07(6.80-7.34)$ & 11.32 & 5.95 \\
\hline Mid-size grocery store & $1.14(1.11-1.18)$ & 1.73 & 0.95 \\
\hline Large supermarket & $1.82(1.80-1.85)$ & 2.01 & $1.7 \varepsilon$ \\
\hline \multicolumn{4}{|l|}{ 1.5-Mile radius } \\
\hline Fast-food restaurant & $15.24(15.06-15.42)$ & 17.45 & 14.66 \\
\hline Full-service restaurant & $5.36(5.28-5.44)$ & 5.98 & 5.20 \\
\hline Convenience store & $4.02(3.95-4.08)$ & 5.15 & 3.72 \\
\hline Small food store & $14.29(13.82-14.76)$ & 22.37 & 12.17 \\
\hline Mid-size grocery store & $2.31(2.25-2.37)$ & 3.33 & 2.05 \\
\hline Large supermarket & $3.70(3.66-3.75)$ & 4.03 & 3.62 \\
\hline \multicolumn{4}{|l|}{ 3.0-Mile radius } \\
\hline Fast-food restaurant & $49.91(49.38-50.45)$ & 57.38 & 47.96 \\
\hline Full-service restaurant & $16.92(16.73-17.12)$ & 18.95 & 16.35 \\
\hline Convenience store & $12.89(12.72-13.06)$ & 16.11 & 12.05 \\
\hline Small food store & $45.91(44.61-47.21)$ & 69.56 & 39.72 \\
\hline Mid-size grocery store & $7.32(7.17-7.47)$ & 9.99 & 6.62 \\
\hline Large supermarket & $11.84(11.70-11.97)$ & 12.90 & 11.56 \\
\hline
\end{tabular}

Abbreviation: CI, confidence interval.

a Means are weighted using California Health Interview Survey sampling weights. Standard errors were obtained through

Taylor series linearization and account for sampling weights and stratification. Buffer size was determined by measuring the distance from the survey respondent's residence.

b All differences are significant $(P<.001)$, based on 2 -sample $t$ test with unequal variances. The federal poverty level, issued annually by the US Department of Health and Human Services, is determined by household income and the number of household members. 
Table 3. Estimated Change (Average Marginal Effect [AME])a in Intake ${ }^{b}$ of Food Item, By Food Outlet Type and Food Environmentc, California, 2007 and 2009

\begin{tabular}{|c|c|c|c|c|c|c|}
\hline \multirow[b]{3}{*}{ Food Item, by Food Outlet Type } & \multicolumn{6}{|c|}{ Buffer Size (Radius) } \\
\hline & \multicolumn{2}{|c|}{ 1.0 Mile } & \multicolumn{2}{|c|}{ 1.5 Mile } & \multicolumn{2}{|c|}{ 3.0 Mile } \\
\hline & AME & $P$ Valued & AME & $P$ Valued & AME & $P$ Valued \\
\hline \multicolumn{7}{|l|}{ Fast-food restaurant } \\
\hline Fruits & -0.023 & .14 & -0.022 & .02 & -0.014 & .001 \\
\hline Vegetables & -0.019 & .20 & -0.025 & .01 & $-0.020 \mathrm{e}$ & $<.001$ \\
\hline Sugar-sweetened soft drinks & 0.057 & .02 & 0.022 & .001 & $0.015^{\mathrm{e}}$ & $<.001$ \\
\hline Fast food & $0.015^{\mathrm{e}}$ & $<.001$ & $0.020 \mathrm{e}$ & $<.001$ & $0.013 \mathrm{e}$ & $<.001$ \\
\hline Fried potatoes & 0.006 & .16 & 0.005 & .03 & $0.005^{\mathrm{e}}$ & $<.001$ \\
\hline \multicolumn{7}{|l|}{ Full-service restaurant } \\
\hline Fruits & 0.034 & .33 & 0.046 & .05 & 0.011 & .36 \\
\hline Vegetables & 0.040 & .30 & 0.046 & .06 & 0.029 & .003 \\
\hline Sugar-sweetened soft drinks & -0.040 & .18 & 0.010 & .63 & 0.004 & .71 \\
\hline Fast food & -0.026 & .03 & -0.030 & .001 & -0.012 & .003 \\
\hline Fried potatoes & -0.010 & .20 & -0.010 & .09 & -0.006 & .06 \\
\hline \multicolumn{7}{|l|}{ Convenience store } \\
\hline Fruits & 0.029 & .43 & -0.013 & .60 & 0.004 & .76 \\
\hline Vegetables & 0.001 & .98 & 0.012 & .57 & 0.009 & .41 \\
\hline Sugar-sweetened soft drinks & -0.013 & .67 & 0.011 & .52 & 0 & .99 \\
\hline Fast food & 0.005 & .72 & 0.005 & .61 & -0.008 & .03 \\
\hline Fried potatoes & 0.002 & .79 & 0.007 & .27 & -0.001 & .85 \\
\hline \multicolumn{7}{|l|}{ Small food store } \\
\hline Fruits & -0.004 & .56 & -0.004 & .41 & -0.003 & .13 \\
\hline Vegetables & -0.001 & .93 & -0.004 & .36 & -0.002 & .27 \\
\hline Sugar-sweetened soft drinks & 0.003 & .61 & 0.001 & .84 & 0 & .90 \\
\hline Fast food & 0.003 & .47 & 0.001 & .74 & 0.001 & .12 \\
\hline Fried potatoes & 0 & .83 & 0 & .73 & 0.001 & .22 \\
\hline \multicolumn{7}{|l|}{ Mid-size grocery store } \\
\hline Fruits & 0.032 & .48 & 0.026 & .42 & 0.025 & .12 \\
\hline Vegetables & 0.031 & .54 & 0.012 & .71 & 0.008 & .56 \\
\hline Sugar-sweetened soft drinks & -0.016 & .62 & -0.038 & .20 & -0.022 & .19 \\
\hline Fast food & -0.054 & .001 & -0.021 & .14 & -0.016 & .02 \\
\hline Fried potatoes & 0.007 & .53 & -0.001 & .90 & -0.004 & .36 \\
\hline \multicolumn{7}{|l|}{ Large supermarket } \\
\hline Fruits & -0.010 & .83 & 0.025 & .44 & 0.028 & .05 \\
\hline Vegetables & -0.013 & .75 & 0.005 & .85 & 0.018 & .14 \\
\hline
\end{tabular}


Preventing Chronic Disease I Neighborhood Food Outlets, Diet, and Obesity Among C... Page 10 of 11

\begin{tabular}{|l|r|r|r|r|r|r|}
\hline \multirow{2}{*}{ Food Item, by Food Outlet Type } & \multicolumn{5}{|c|}{ Buffer Size (Radius) } \\
\cline { 2 - 7 } & \multicolumn{2}{|c|}{$\mathbf{1 . 0}$ Mile } & \multicolumn{2}{|c|}{$\mathbf{1 . 5}$ Mile } & \multicolumn{2}{c|}{$\mathbf{3 . 0}$ Mile } \\
\cline { 2 - 7 } & \multicolumn{1}{|c|}{ AME } & \multicolumn{1}{|c|}{$\boldsymbol{P}$ Valued } & \multicolumn{1}{c|}{ AME } & \multicolumn{1}{c|}{$\boldsymbol{P}$ Valued } & \multicolumn{1}{c|}{ AME } & $\boldsymbol{P}$ Valued $^{-1}$ \\
\hline Sugar-sweetened soft drinks & -0.130 & $<.001$ & $-0.106 \mathrm{e}$ & $<.001$ & $-0.051 \mathrm{e}$ & $<.001$ \\
\hline Fast food & -0.026 & .10 & -0.030 & .003 & -0.020 & .002 \\
\hline Fried potatoes & -0.013 & .25 & -0.013 & .07 & -0.010 & .009 \\
\hline
\end{tabular}

a AMEs measure an estimated change in the per-week frequency of consumption of each food item associated with 1 unit change in the regressor of interest.

b Number of times the item was consumed per week.

c Food environment was defined by counting the number of food outlet types (eg, supermarket) in each buffer of a certain radius (eg, 1.0 mile) centered on a respondent's residence. Statistics were adjusted by using California Health Interview Survey sampling weights.

$\mathrm{d} P$ values were calculated by using $z$ statistic obtained through negative binomial regression and based on standard errors estimated using the Eicker-Huber-White sandwich estimator.

e AME is different from zero (at .05 level) after applying Bonferroni's adjustment for multiple comparisons. All 6 food outlet types were included in the regression models, and individual- and census tract-level characteristics were controlled for (but are not presented here).

Table 4. Estimated Change (Average Marginal Effect [AME]a) in Body Mass Index (BMI) and the Probability of Overweight or Obesity, by Food Outlet Type and Food Environment, California, 2007 and 2009

\begin{tabular}{|c|c|c|c|c|c|c|}
\hline \multirow[b]{3}{*}{ Food Outlet Type/BMI Measure } & \multicolumn{6}{|c|}{ Buffer Size (Radius) } \\
\hline & \multicolumn{2}{|c|}{1.0 Mile } & \multicolumn{2}{|c|}{1.5 Mile } & \multicolumn{2}{|c|}{ 3.0 Mile } \\
\hline & AME & $P$ Value $^{c}$ & AME & $P$ Value $^{c}$ & AME & $P$ Value \\
\hline \multicolumn{7}{|l|}{ Fast-food restaurant } \\
\hline BMI & 0.020 & .07 & 0.010 & .17 & 0.009 & .02 \\
\hline $\mathrm{BMI} \geq 25.0$ & 0.001 & .23 & 0.001 & .11 & $0.001^{d}$ & $<.001$ \\
\hline BMI $\geq 30.0$ & 0.001 & .35 & 0 & .62 & 0.001 & .006 \\
\hline \multicolumn{7}{|l|}{ Full-service restaurant } \\
\hline BMI & -0.059 & .02 & -0.014 & .47 & 0.010 & .27 \\
\hline $\mathrm{BMI} \geq 25.0$ & -0.003 & .26 & -0.001 & .48 & 0 & .59 \\
\hline BMI $\geq 30.0$ & -0.003 & .12 & 0 & .92 & 0 & .91 \\
\hline \multicolumn{7}{|l|}{ Convenience store } \\
\hline BMI & 0.007 & .79 & -0.005 & .78 & 0.003 & .73 \\
\hline BMI $\geq 25.0$ & -0.002 & .34 & -0.002 & .18 & -0.001 & .31 \\
\hline BMI $\geq 30.0$ & 0.002 & .19 & 0.001 & .47 & 0 & .65 \\
\hline \multicolumn{7}{|l|}{ Small food store } \\
\hline BMI & 0.005 & .47 & 0.001 & .86 & -0.001 & .32 \\
\hline BMI $\geq 25.0$ & 0 & .91 & 0 & .54 & 0 & .82 \\
\hline $\mathrm{BMI} \geq 30.0$ & 0 & .39 & 0 & .89 & 0 & .83 \\
\hline \multicolumn{7}{|l|}{ Mid-size grocery store } \\
\hline BMI & -0.029 & .44 & -0.002 & .93 & 0 & $>.99$ \\
\hline $\mathrm{BMI} \geq 25.0$ & -0.003 & .34 & -0.003 & .19 & 0 & .79 \\
\hline BMI $\geq 30.0$ & -0.005 & .04 & -0.002 & .30 & -0.001 & .42 \\
\hline
\end{tabular}




\begin{tabular}{|c|c|c|c|c|c|c|}
\hline \multirow[b]{3}{*}{ Food Outlet Type/BMI Measure } & \multicolumn{6}{|c|}{ Buffer Size (Radius) } \\
\hline & \multicolumn{2}{|c|}{1.0 Mile } & \multicolumn{2}{|c|}{1.5 Mile } & \multicolumn{2}{|c|}{ 3.0 Mile } \\
\hline & AME & $P$ Valuec & AME & $P$ Valuec & AME & $P$ Valuec \\
\hline \multicolumn{7}{|l|}{ Large supermarket } \\
\hline BMI & $-0.115^{d}$ & $<.001$ & $-0.093^{d}$ & $<.001$ & $-0.073^{d}$ & $<.001$ \\
\hline BMI $\geq 25.0$ & -0.008 & .003 & $-0.008^{d}$ & $<.001$ & $-0.005^{d}$ & $<.001$ \\
\hline BMI $\geq 30.0$ & -0.007 & .001 & -0.006 & .001 & $-0.005^{d}$ & $<.001$ \\
\hline
\end{tabular}

a AME on BMI reflects the estimated change in BMI (in $\mathrm{kg} / \mathrm{m}^{2}$ ); AME on BMI $\geq 25$ (or BMI $\geq 30$ ) reflects the estimated change in the probabilities of being overweight or obese (or of being obese) associated with 1 unit change in the regressor of interest.

b Food environment was defined by counting the number of food outlet types (eg, supermarket) in each buffer of a certain radius (eg, 1.0 mile) centered on a respondent's residence. Statistics were adjusted by using California Health Interview Survey sampling weights.

c $P$ value for BMI was calculated by using $t$ statistic obtained through ordinary least squares regression. $P$ value for $B M I \geq 25$ and BMI $\geq 30$ was calculated by using $z$ statistic obtained through logistic regression and based on standard errors estimated using the Eicker-Huber-White sandwich estimator.

d AME is different from zero (at .05 level) after adjustment for multiple comparisons. All 6 food outlet types were included in the regression models, and individual- and census tract-level characteristics were controlled for (but are not presented here).

The opinions expressed by authors contributing to this journal do not necessarily reflect the opinions of the U.S. Department of Health and Human Services, the Public Health Service, the Centers for Disease Control and Prevention, or the authors' affiliated institutions.

The RIS file format is a text file containing bibliographic citations. These files are best suited for import into bibliographic management applications such as EndNote download is available at each application's web site.

For Questions About This Article Contact pcdeditor@cdc.gov

Page last reviewed: March 14, 2013

Page last updated: March 14, 2013

Content source: National Center for Chronic Disease Prevention and Health Promotion

Centers for Disease Control and Prevention 1600 Clifton Rd. Atlanta, GA 30333, USA

80o-CDC-INFO (800-232-4636) TTY: (888) 232-6348 - Contact CDC-INFO 